\title{
APRESENTAÇÃO
}

Inicialmente, gostaria de agradecer a todos aqueles que apresentaram seus textos para publicação neste número da Revista de Estudos da Linguagem, dedicado aos trabalhos apresentados no VII Congresso Nacional de Fonética e Fonologia e I Congresso Internacional de Fonética e Fonologia, que se realizou em Belo Horizonte em outubro de 2002. Agradeço a paciência com que aguardaram a longa edição da revista. Fizemos o possível para que todos os problemas apresentados tivessem uma solução. Apresentamos nossas desculpas pelas eventuais falhas, que são de nossa inteira responsabilidade. Nossa meta era a publicação antes do Congresso de São Luís, meta essa, que foi atingida, graças à colaboração de colegas, estudantes, funcionários e dos autores.

Os artigos apresentados, com poucas exceções, estão sendo publicados, oferecendo uma visão dos grupos, indivíduos, temas e metodologias que constituem a pesquisa em Fonética e Fonologia da língua portuguesa no país e no exterior. Como há alguns textos de autores portugueses, respeitamos suas convenções ortográficas, da mesma forma como respeitamos as convenções de transcrição fonética dos diferentes autores.

Teoria Fonológica, Língua Estrangeira, Fala Patológica, Aquisição Fonológica, Prosódia, Fonética Experimental são os temas que agrupam o maior número de trabalhos. Na verdade, podemos dividir os trabalhos em dois grandes grupos: Fonética Experimental e Teoria Fonológica. Tomando-se aqui Fonética Experimental num sentido amplo, isto é, a simples utilização de métodos da física, da fisiologia ou da psicologia no estudo dos sons da fala. Fazemos abaixo uma breve apresentação dos trabalhos aqui publicados, uma vez que estarão sempre precedidos do respectivo abstract. 


\section{Fonética Experimental}

Em ANGELA MARIA VIEIRA PINHEIRO (UFMG) e CÉSAR REIS (UFMG), A influência da natureza fonética do fonema inicial da palavra na medida de tempo de reação em tarefas de leitura em voz alta, os autores analisam o efeito da natureza fonética de vários fonemas em posição inicial de palavras regulares de alta freqüência no tempo de reação em tarefas de leitura em voz alta;

CARLOS TOSHINORI ISHI (Laboratórios ATR/HIS) e NICK CAMPBELL (Laboratórios ATR/HIS), Analysis of acoustic-prosodic features of spontaneous expressive speech, com base em vários parâmetros acústicos, visando à síntese da fala, investigam a participação desses parâmetros acústicos, assim como a existência de correlação entre eles, na manifestação de diferentes emoções e atitudes, com base em dados da fala espontânea do japonês;

RICARDO AUGUSTO HOFFMANN BION (UFSC), O uso de estímulos sintéticos em testes de percepção de vogais de uma língua estrangeira, realiza testes de percepção com estudantes brasileiros, sendo os estímulos vogais anteriores do inglês;

Em ANTONIO TEIXEIRA (Universidade de Aveiro), FRANCISCO VAZ (Universidade de Aveiro), LURDES CASTRO MOUTINHO (Universidade de Aveiro), ROSA LÍDIA COIMBRA (Universidade de Aveiro), RAQUEL CASTRO LISBOA (Universidade de Aveiro), Para a melhoria da sintese articulatória das vogais nasais do Português Europeu: estudo da duração e de características relacionadas com a fonte glotal, os autores apresentam um estudo acústico e glotográfico de vários parâmetros da fonte glotal;

ANTÓNIO ROMANO (Università di Torino) e LURDES DE CASTRO MOUTINHO (Universidade de Aveiro), Alguns esquemas entoacionais característicos da leitura de um texto por portugueses e brasileiros, fazem um estudo comparativo de entonações do português brasileiro e português europeu;

LURDES DE CASTRO MOUTINHO (Universidade de Aveiro) e JEAN-PIERRE ZERLING (Universidade Marc Bloch), Análise comparada de três padrões prosódicos em Francês e em Português 
Europeu, é um estudo prosódico em que são comparados enunciados declarativo, interrogativo e imperativo do português europeu e do francês;

LARISSA CIRÍACO (UFMG), LORENZO TEIXEIRA VITRAL (UFMG), CÉSAR REIS (UFMG), Intensidade e duração de formas reduzidas no português brasileiro, apresentam um estudo fonético acústico de algumas formas reduzidas do português brasileiro em processo de cliticização;

RUI ROTHE-NEVES (UFMG), REGINA CARLA LAPATE (UFMG) e JULIANA SARDINHA PINTO (UFMG), Tarefa de discriminação de fonemas com pseudopalavras, apresentam uma tarefa de discriminação de fonemas por pacientes afásicos;

ERICA REVIGLIO ILIOVITZ (UNICAMP), Reorganização prosódica na disartria, apresenta um estudo prosódico longitudinal de dois pacientes com disartria pós-traumática;

JUSSARA MELO VIEIRA, PLÍNIO ALMEIDA BARBOSA (UNICAMP), MARIA INÊS PEGORARO-KROOK, A pausa na produção da fala com comprometimento neurológico, estudam a pausa em um indivíduo com disartria e incompetência velofaríngea, examinando a correlação entre a duração das pausas e a natureza da fronteira sintática;

REGINA CÉLIA FERNANDES CRUZ (UFPA), JAILMA DO SOCORRO UCHÔA BULHÕES (UFPA) e LÉA DA SILVA FERNANDES (UFPA), Banco de Dados Orais: uma nova perspectiva aos estudos do português brasileiro, apresentam um banco de dados orais destinado aos pesquisadores sociolingüistas e foneticistas.

\section{Teoria Fonológica}

JOSÉ OLÍMPIO DE MAGALHÃES (UFMG) e MAÍRA MARTINS (UFMG), O caminho para a realização de / l / e/r / intervocálicos na aquisição com atraso: a substituição por [ $j$ ], verificam algumas hipóteses nas etapas de aquisição dos fonemas / / e / $\mathbf{~ / ~ e m ~ c r i a n c ̧ a s ~}$ com atraso de linguagem; 
THAÏS CRISTÓFARO-SILVA (UFMG) e DANIELA MARA LIMA OLIVEIRA (UFMG), Seqüências de (sibilante + consoante) noportuguês de Belo Horizonte, examinam a variação sonora nas seqüências (sibilante + oclusiva alveolar) e (sibilante + africada alveopalatal);

MARIA DO CARMO VIEGAS (UFMG), O alçamento das vogais médias pretônicas e o conceito de léxico com armazenamento exemplar, apresenta reflexões teóricas sobre o alçamento da vogal média pretônica;

LUCIANA TENANI (UNESP/SJRP), A importância $d a$ proeminência da frase fonológica no português brasileiro, estuda a inter-relação entre a estrutura prosódica, no caso a frase fonológica, e os processos fonológicos de degeminação e elisão;

FILOMENA SANDALO (UNICAMP), Fonologia Prosódica e Teoria da Otimalidade: Reflexões sobre a interface sintaxe e fonologia na formação de sintagmas fonológicos, trata de temas teóricos envolvendo as relações entre sintaxe e prosódia, enfocando-os com base na ocorrência do choque acentual;

RAQUEL S. SANTOS (USP), Retração acentual e verbos transitivos com leitura intransitiva, trata da retração acentual vista do ponto de vista das relações entre a fonologia e a sintaxe;

IRENE ZASIMOWICZ PINTO CALAÇA (UFMG), Da frase fonológica no dialeto goiano, estuda alguns aspectos prosódicos e fonologicos dentro da frase fonológica;

RENÉE LAMBERT (Université Lumière-Lyon 2), Diminutive reduplication in Government Phonology, se baseia em dados de reduplicação em várias línguas para fundamentar suas reflexões teóricas sobre a representação morfológica e fonológica de algumas categorias lexicais;

FERNANDA ELIAS ZUCARELLI (Faculdades Integradas FAFIBE), Breve estudo da estrutura silábica do português arcaico: a posição do glide, analisa a posição da semivogal na estrutura silábica no português arcaico;

TERESINHA DE MORAES BRENNER (UFSC), Traço fonológico: variação sob a perspectiva da multilinearidade, examina alguns 
fenômenos de variação fonológica no português brasileiro com base na teoria da Geometria de Traços;

REGINA CÉLIA FERNANDES CRUZ(UFPA) e HELANE DE FÁTIMA GOMES FERNANDES (UFPA), Simbolismo sonoro do PB: o estudo dos ideofones, analisam processos de formação de ideofones no PB;

ANDRÉIA SCHURT RAUBER (UFSC) E BARBARA OUGHTON BAPTISTA (UFSC), The production of English initial /s/ clusters by Portuguese and Spanish EFL speakers, tratam da produção de encontros consonantais iniciais ( $\mathrm{sC}(\mathrm{C})$ ) em inglês por falantes do português e do espanhol, procurando extrair resultados teóricos e pedagógicos;

BARBARA O. BAPTISTA (UFSC), Categorias fonéticas na aprendizagem de lingua estrangeira, examina dois modelos de aprendizagem dos sons de língua estrangeira;

MAGLIANE DE MARCO (Universidade Católica de Pelotas), $A$ aquisição de encontros consonantais do inglês iniciados por $/ \mathrm{s} /$ : estudo de caso com criança brasileira, estuda a aquisição de encontros consonantais do inglês iniciados por /s/ por uma criança brasileira, buscando na teoria fonológica explicações para os fatos observados;

NINA A. LYUBIMOVA (UFRGS), Interpretação fonológica e realização fonética durante o aprendizado de uma $L E$, trata de uma unidade fônica especial que surge no processo de aquisição de uma língua estrangeira e que denomina de diafonema;

TANIRA CASTRO (UFRGS), A identificação fonêmica do discurso de estudantes brasileiros na lingua russa, apresenta um estudo sobre as dificuldades dos estudantes brasileiros na aquisição da pronúncia da língua russa. 